\title{
The 10-Year Incidence Trend of Common Cancers at a Referral Hospital in Tehran, Iran From 2007 to 2016
}

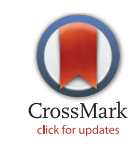

\author{
Hormoz Sanaeinasab ${ }^{1}$, Esmat Davoudi Monfared ${ }^{2}{ }^{*}$, Ali-Akbar Karimi Zarchi ${ }^{3}$, Mohsen Saffari ${ }^{1}$, \\ Abdowreza Delavari ${ }^{4}$
}

${ }^{1}$ Health Research Center \& Health Education Department, Faculty of Health, Baqiyatallah University of Medical Sciences, Tehran, Iran

${ }^{2}$ Health Management Research Center \& Department of Community Medicine, Faculty of Medicine, Baqiyatallah University of Medical Sciences, Tehran, Iran

${ }^{3}$ Department of Epidemiology and Biostatistics, Faculty of Health, Baqiyatallah University of Medical Sciences, Tehran, Iran

${ }^{4}$ Department of Management, Baqiyatallah University of Medical Sciences, Tehran, Iran

*Corresponding Author: Esmat Davoudi Monfared, M.D., Associate Professor, Health Management Research Center \& Department of Community Medicine, Faculty of Medicine, Baqiyatallah University of Medical Sciences, Tehran, Iran. Tel: +98-2181263850, Email: davoudimonfared@gmail.com

Received June 15, 2018; Accepted September 6, 2018; Online Published September 20, 2019

\begin{abstract}
Background: Common cancers such as colon, breast, and lung cancer are increasing in developing countries.

Objective: This study was conducted to determine 10-year trends and changes in common cancers in patients from a referral hospital in Tehran, Iran.

Methods: This cross-sectional study investigated a study population comprising colon, stomach, lung, prostate, and breast cancer patients registered at the cancer center of a referral hospital in Tehran, Iran from April 1, 2007 to the end of March, 2016 ( $n=4472$ ). Inclusion criteria were a definitive diagnosis of cancer and an age between 15 and 75 years. Data was entered into SPSS (version 18) software and analyzed using the Time Series analysis and Scatter IO graph.

Results: Significant correlations $(P$ value $<0.001)$ were seen between age increases in patients and the increasing number of patients in any type of cancer. With almost all of the five studied cancers, incidence increased with aging $(P$ value $<0.001)$. The incremental linear trend in the age of patients with lung $(P$ value $=0.008)$ and colon $(P$ value $=0.004)$ cancers and the decreasing trend in the age of prostate cancer patients $(P$ value $=0.001)$ were statistically significant.

Conclusion: The incidence of cancer has increased over the past 10 years in both genders and ages. It is suggested that future studies should address the causes and factors behind the increasing incidence of common cancers.

Keywords: Cancers, Trend, Incidence, Iran
\end{abstract}

\section{Background}

The incidence of cancer is rising over time; it is estimated that by 2030, the death rate will increase to 12 million per year and the burden of the disease will be more than doubled. ${ }^{1}$ The annual incidence of cancers in Iran is about 70000 , and the mortality rate is about 30000 people. $^{2}$ While the incidence and mortality rates of most cancers (including lung, colorectal, and breast) in the United States and many western countries are declining, in less developed countries they are increasing. ${ }^{3,4}$

The incidence of cancer is increasing in developing countries as a result of population aging and increasing risk factors such as smoking, physical inactivity, obesity, stress, etc. ${ }^{5}$ The prevalence of smoking among adult males in the West, including the United States, is about 20\% compared with more than $60 \%$ in China, Indonesia, and Jordan. ${ }^{6}$ Therefore, a new warning trend has begun on cancer prevalence in these countries. ${ }^{7,8}$ Common cancers such as colon, breast, and lung cancers are now often increasing in developing countries.9, 10

Studies in Iran have shown that the incidence rates of breast cancer among Iranian women and of prostate cancer among Iranian men are increasing. ${ }^{11,} 12$ The incidence of stomach cancer is also increasing due to increases in its risk factors. ${ }^{13}$

\section{Objective}

Given the evidence for increased cancer incidence in Iran, recognizing the age-related trends of cancers over a long period of time seems to be very necessary. Considering that

Copyright $\odot 2019$ The Author(s). This is an open-access article distributed under the terms of the Creative Commons Attribution License (http:// creativecommons.org/licenses/by/4.0), which permits unrestricted use, distribution, and reproduction in any medium, provided the original work is properly cited. 
no study has been done on cancer trends in the hospitals of Tehran, Iran, this study was conducted to determine the 10 -year trends and changes in common cancers among patients referred to Baqiyatallah hospital.

\section{Methods}

This cross-sectional study investigated a study population comprising all cancer patients registered at the cancer center of a referral hospital in Tehran, Iran from April 2007 to March 2016.

The sample included all patients admitted with malignant tumors of the colon, stomach, lung, prostate, or breast in any stage of disease and registered in the hospital electronic records $(n=4472)$. The inclusion criteria included a definitive diagnosis of cancer and an age between 15 and 75 years. The research was conducted using a researcherdeveloped information registration form and referring to the patients' electronic records.

The questionnaire consisted of two parts: patients' demographics and disease information. Demographic data included age, gender, and region of residence in Tehran; disease information including type, grade, and stage of cancer.

\subsection{Data analysis}

After the data was entered onto the relevant forms, it was analyzed using SPSS (version 18) software. Data explorations were then performed. In this way, the outlier and missing data were examined. In order to achieve the descriptive study objectives, mean, standard deviation, and other dispersion indices for quantitative variables and frequency tables and graphs for qualitative variables were prepared. The final analysis was carried out using Time Series analysis and Scatter IO graph.

\section{Results}

The mean age of cancer patients was $57.08 \pm 16.48$ years, and $47.6 \%$ of them were male. Stomach, colon, prostate, and lung cancers were significantly higher in men than in women $(P$ value $<0.001)$.

Most of the diagnosed patients were over the age of 60 years (2120). Breast cancer (33.7\%) and colon cancer (33.4\%) were the most commonly reported cancers. There was a significant correlation $(P$ value $<0.001)$ between the increasing age of patients and the increasing incidence of any type of cancer, such that in almost all five studied cancer types, the incidence of cancer increased with aging (Table 1 and Figure 1). There was also a great deal of fluctuation in the incidence of cancer from year to year, with cancer type varying from one year to the next. A significant correlation ( $P$ value $<0.001)$ was seen between incidence and type of cancer (Table 1 ).

No statistically significant difference was observed between the mean age of patients and stomach $(P$ value $=$ 0.1 ) or breast $(P$ value $=0.18)$ cancers during the studied years, but the linear trend of age in patients with lung $(P$ value $=0.008)$ and colon $(P$ value $=0.004)$ cancers as well as the decreasing trend in the age of patients with prostate cancer $(P$ value $=0.001)$ were statistically significant (Figure 2).

Table 1. Comparison of the Incidence of Cancer in Different Age Groups During the Years 2007 to 2016

\begin{tabular}{|c|c|c|c|c|c|c|}
\hline \multirow{2}{*}{ Variable } & \multicolumn{5}{|c|}{ Cancer type } & \multirow{2}{*}{ Total } \\
\hline & Stomach & Colon & Breast & Prostate & Lung & \\
\hline \multicolumn{7}{|l|}{ Sex } \\
\hline Male & $419(19.8 \%)$ & $888(42.0 \%)$ & $34(1.6 \%)$ & $565(26.8 \%)$ & $206(9.8 \%)$ & $2112(100 \%)$ \\
\hline Female & $202(8.7 \%)$ & 587 (25.2\%) & $1466(63.0 \%)$ & $1(0.0)$ & $70(3.0 \%)$ & $2326(100 \%)$ \\
\hline \multicolumn{7}{|l|}{ Age } \\
\hline$\leq 20$ & $3(2.7 \%)$ & $26(23.4 \%)$ & $79(71.2 \%)$ & $0(0.0)$ & $3(2.7 \%)$ & $111(100 \%)$ \\
\hline $21-30$ & $10(4.0 \%)$ & $53(21.4 \%)$ & $174(70.2 \%)$ & $0(0.0)$ & $11(4.4 \%)$ & $248(100 \%)$ \\
\hline $31-40$ & 35 (11.9\%) & $52(17.6 \%)$ & $200(67.8 \%)$ & $0(0.0)$ & $8(2.7 \%)$ & $295(100 \%)$ \\
\hline $41-50$ & $63(7.8 \%)$ & $240(29.6 \%)$ & $458(56.5 \%)$ & $16(2.0 \%)$ & $34(4.2 \%)$ & $811(100 \%)$ \\
\hline $51-60$ & $118(13.3 \%)$ & $356(40.1 \%)$ & 289 (32.6\%) & $72(8.1 \%)$ & $52(5.9 \%)$ & $887(100 \%)$ \\
\hline$>60$ & $398(18.8 \%)$ & 767 (36.2\%) & $309(14.6 \%)$ & $478(22.5 \%)$ & $168(7.9 \%)$ & $2120(100 \%)$ \\
\hline \multicolumn{7}{|l|}{ Year } \\
\hline 2007 & $8(11.4 \%)$ & $12(17.1 \%)$ & $37(52.9 \%)$ & $7(10.0 \%)$ & $6(8.6 \%)$ & $70(100 \%)$ \\
\hline 2008 & 55 (15.6\%) & $83(23.6 \%)$ & $141(40.1 \%)$ & $55(15.6 \%)$ & $18(5.1 \%)$ & $352(100 \%)$ \\
\hline 2009 & 77 (16.9\%) & $117(25.7 \%)$ & $155(34.1 \%)$ & $79(17.4 \%)$ & $27(5.9 \%)$ & $455(100 \%)$ \\
\hline 2010 & $11(2.7 \%)$ & $158(38.2 \%)$ & $173(41.8 \%)$ & $41(9.9 \%)$ & $31(7.5 \%)$ & $414(100 \%)$ \\
\hline 2011 & $102(18.8 \%)$ & 192 (35.4\%) & $178(32.8 \%)$ & $43(7.9 \%)$ & $27(5.0 \%)$ & $542(100 \%)$ \\
\hline 2012 & $113(15.3 \%)$ & $382(51.8 \%)$ & $162(22.0 \%)$ & $58(7.9 \%)$ & $22(3.0 \%)$ & 737 (100\%) \\
\hline 2013 & $27(6.2 \%)$ & $136(31.3 \%)$ & 171 (39.4\%) & $66(15.2 \%)$ & $34(7.8 \%)$ & $434(100 \%)$ \\
\hline 2014 & $32(7.5 \%)$ & $123(28.8 \%)$ & 167 (39.1\%) & $70(16.4 \%)$ & $35(8.2 \%)$ & $427(100 \%)$ \\
\hline 2015 & $102(19.0 \%)$ & $160(29.9 \%)$ & $160(29.9 \%)$ & $65(12.1 \%)$ & 49 (9.1\%) & $536(100 \%)$ \\
\hline 2016 & $100(19.7 \%)$ & $132(26.0 \%)$ & $166(32.7 \%)$ & $82(16.2 \%)$ & $27(5.3 \%)$ & $507(100 \%)$ \\
\hline Total & $627(14.0 \%)$ & $1494(33.4 \%)$ & $1509(33.7 \%)$ & $566(12.7 \%)$ & $276(6.2 \%)$ & $4472(100 \%)$ \\
\hline
\end{tabular}




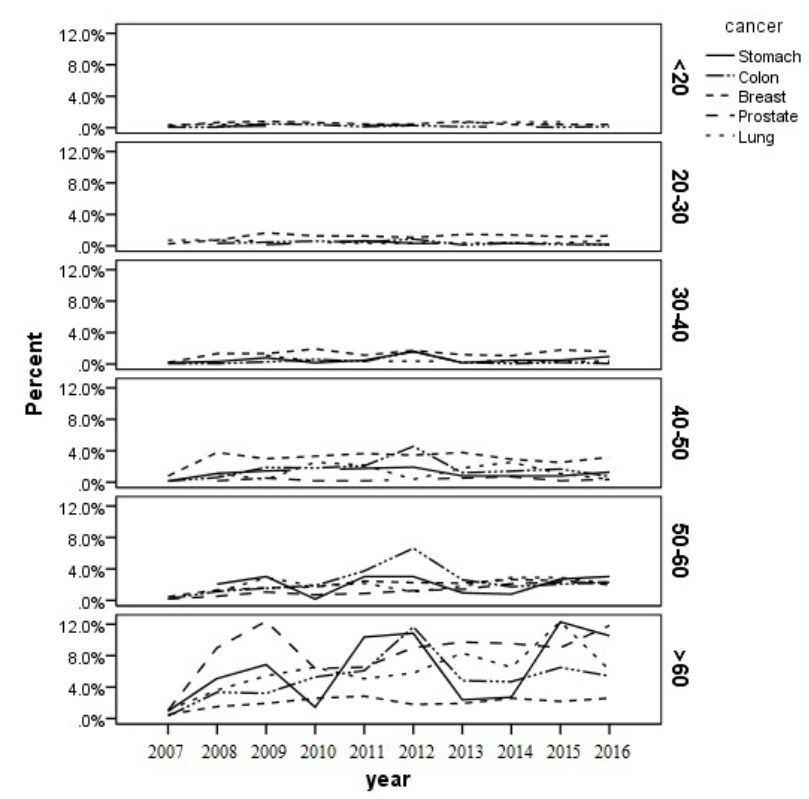

Figure 1. Comparison of the Incidence of Cancer in Different Age Groups During the Years 2007 to 2016

As seen in Table 2, cancers of the stomach were seen in $84 \%$ and $57 \%$ of the males and females, respectively, representing a significant difference $(P$ value $<0.001)$. Cancers were more common in males than in females, but the difference between colon $(P$ value $=0.16)$ and lung $(P$ value $=0.39)$ cancer patients was not statistically significant.

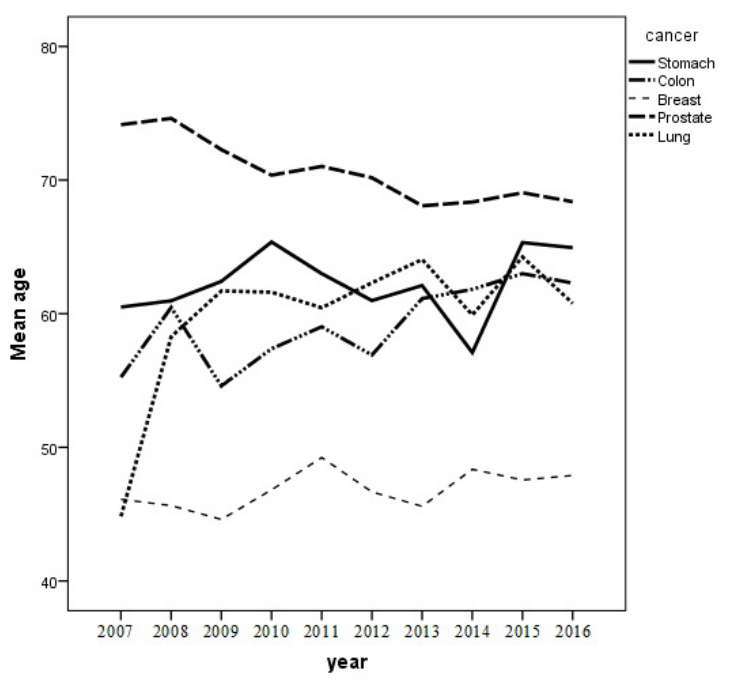

Figure 2. Evaluation of the Age Trends in Patients by Cancer Type During 2007-2016

As age increased, cancers of the stomach $(P$ value $<0.001)$, colon $(P$ value $<0.001)$, and breast $(P$ value $<0.001)$ also increased significantly. However, there was no statistically significant difference between the levels of prostate $(P$ value $=0.48)$ and lung $(P$ value $=0.29)$ cancers in different age groups.

There was a significant increase in the incidence of colon cancer from year to year $(P$ value $<0.001)$, but the results of this study showed that cancers of the stomach $(P$ value $=$ $0.84)$, breast $(P$ value $=0.54)$, prostate $(P$ value $=0.25)$, and

Table 2. Distribution of Cancers by Gender, Different Age Groups and Years of Occurrence

\begin{tabular}{|c|c|c|c|c|c|}
\hline & Stomach Cancer & Colon Cancer & Breast Cancer & Prostate Cancer & Lung Cancer \\
\hline \multicolumn{6}{|l|}{ Sex } \\
\hline Male & $352(84 \%)$ & $365(41.1 \%)$ & $28(82.4 \%)$ & $562(99.5 \%)$ & $199(96.6 \%)$ \\
\hline Female & $116(57.4 \%)$ & $220(37.5 \%)$ & 1107 (75.5\%) & $1(100 \%)$ & $66(94.3 \%)$ \\
\hline \multicolumn{6}{|l|}{ Age } \\
\hline$\leq 20$ & $1(33.3 \%)$ & $4(15.4 \%)$ & $2(2.5 \%)$ & $0(0)$ & $2(66.7 \%)$ \\
\hline $21-30$ & $5(50 \%)$ & $17(32.1 \%)$ & $25(14.4 \%)$ & $0(0)$ & $11(100 \%)$ \\
\hline $31-40$ & $19(54.3 \%)$ & $21(40.4 \%)$ & $140 .(70 \%)$ & $0(0)$ & $7(87.5 \%)$ \\
\hline $41-50$ & $34(54 \%)$ & $82(34.2 \%)$ & $401(87.6 \%)$ & $16(100 \%)$ & $33(97.1 \%)$ \\
\hline $51-60$ & $95(80.5 \%)$ & $140(39.3 \%)$ & $276(95.5 \%)$ & $72(100 \%)$ & $50(96.2 \%)$ \\
\hline$>60$ & $319(80.2 \%)$ & 331 (43.2\%) & $300(97.1 \%)$ & $475(99.4 \%)$ & $162(96.4 \%)$ \\
\hline \multicolumn{6}{|l|}{ Year } \\
\hline 2007 & $7(87.5 \%)$ & $4(33.3 \%)$ & $25(67.6 \%)$ & $7(100 \%)$ & $5(83.3 \%)$ \\
\hline 2008 & $50(90.9 \%)$ & $47(56.6 \%)$ & $105(74.5 \%)$ & $55(100 \%)$ & 17 (94.4\%) \\
\hline 2009 & $56(72.7 \%)$ & $42(35.9 \%)$ & $108(69.7 \%)$ & $79(100 \%)$ & 27 (100\%) \\
\hline 2010 & $10(90.9 \%)$ & $61(38.6 \%)$ & $137(79.2 \%)$ & $41(100 \%)$ & $31(100 \%)$ \\
\hline 2011 & $82(80.4 \%)$ & $47(24.5 \%)$ & $149(83.7 \%)$ & $42(97.7 \%)$ & $26(96.3 \%)$ \\
\hline 2012 & $75(66.4 \%)$ & $79(20.7 \%)$ & $124(76.5 \%)$ & $58(100 \%)$ & $20(90.9 \%)$ \\
\hline 2013 & $8(29.6 \%)$ & $72(52.9 \%)$ & $122(71.3 \%)$ & $66(100 \%)$ & $32(94.1 \%)$ \\
\hline 2014 & $8(25 \%)$ & $83(67.5 \%)$ & $121(72.5 \%)$ & $70(100 \%)$ & 35 (100\%) \\
\hline 2015 & $84(82.4 \%)$ & $86(53.8 \%)$ & $125(78.1 \%)$ & $64(98.5 \%)$ & $46(93.9 \%)$ \\
\hline 2016 & $93(93 \%)$ & $74(56.1 \%)$ & $128(77.1 \%)$ & $81(98.8 \%)$ & $26(96.3 \%)$ \\
\hline
\end{tabular}




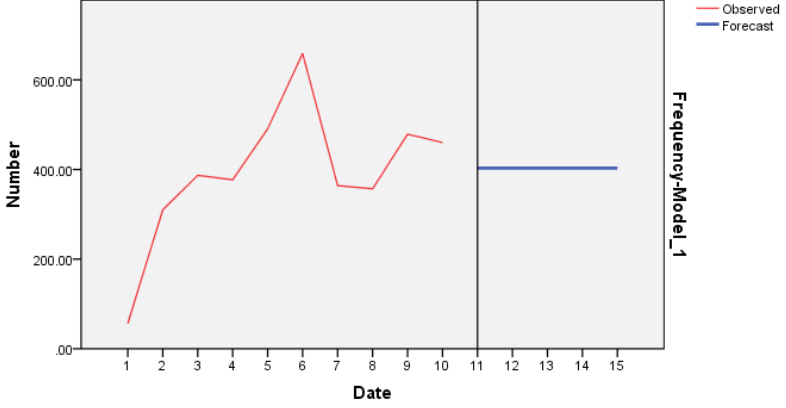

Figure 3. Prediction of Frequency of Cancer Patients Referred to Baqiyatallah Hospital.

lung $(P$ value $=0.85)$ did not increase in different years. Figure 3 shows the predicted frequency of cancer patients.

\section{Discussion}

The current study showed that the number of patients with common cancers admitted to the hospital has increased over the past 10 years. Previous studies have shown that from 2007 to 2015, developed countries had the highest incidence rates of lung, colorectal, breast, and prostate cancers, but mortality rates declined during this period. Conversely, in developing countries, while the incidence of common cancers increased, the highest mortality rates were associated with these cancers. ${ }^{14}$ Causes of the increased incidence of stomach, colon, breast, prostate, and lung cancers in developed and developing countries are associated with increased risk factors for these cancers. ${ }^{15}$ Smoking, body weight, and physical inactivity, which are related to lifestyle, have increased among the general population, and these factors have increased the risk of most cancers in developed and developing countries during this period. ${ }^{16}$ Although incidence rates of common cancers in developed countries have increased, screening and early detection of common cancers (e.g., breast and colon cancers) and the progression and improvement in the treatment of these cancers have caused the incidence of common cancers to decrease in these countries. ${ }^{17}$

In the current study, breast cancer with a prevalence of $33.7 \%$ was found to be the most common cancer among the studied patients. Breast cancer in Iran is seen mostly in patients nearly ten years younger than patients in developed countries; more than $30 \%$ of breast cancer patients are under the age of $30 .{ }^{18}$ The breast cancer mortality rate has been decreasing in developed countries since the 1990s through breast cancer screening, early diagnosis, and effective treatment. ${ }^{19}$ In Iran, however, early screening methods have not yet been established, and the breast cancer mortality rate remains high. Due to breast cancer risk factors, such as lack of delivery and lactation, pregnancy at a higher age, and the use of OCP and HRT, ${ }^{6}$ an increased incidence of breast cancer is expected. It is suggested that population-based screening, timely diagnosis, and appropriate treatment of this cancer be generally implemented.

In the current study, colon cancer with an incidence
Research Highlights

What Is Already Known?

While the incidence and mortality rates of most cancers (including lung, colorectal, and breast) in the United States and many western countries are declining, they are increasing in less developed countries, such as Iran.

\section{What This Study Adds?}

The findings of the current study suggest that considerable increasing trends of common cancers have occurred over the past 10 years and all cancers increased with increases in patient age.

of $33.4 \%$ was the second most common cancer among the patients, and there was a significant increase in the incidence of colon cancer over the years. Studies have shown that colon cancer prevalence and mortality rates in Iran increased in the years 1996-2004. ${ }^{20,21}$ The implementation of national colon cancer screening in Iran could also effectively identify people at risk, aid in the early detection of affected people, and consequently, reduce the colon cancer mortality rate.

Among men, lung cancer has the highest mortality rate among cancers. Women also have a higher risk of mortality from lung cancer in countries where they have the highest levels of smoking (such as the United States, England, and Australia). ${ }^{22}$ This study also found that the difference in the rate of lung cancer between women and men was not statistically significant, which could be a warning sign of an increased prevalence of smoking among Iranian women.

In recent years, the prevalence of smoking has declined in some developed countries, ${ }^{23}$ while it is increasing in developing countries such as Iran and among the women of these countries. In the same period, mortality from smoking in developing countries will double. ${ }^{24}$ Preventing people from starting to smoke and promoting smoking cessation programs can reduce the mortality from lung cancer. It seems that these programs in Iran, especially for women, should be implemented more seriously.

In this study, the incidence of all cancers increased with increases in age, with the exception of prostate cancer, which showed no statistically significant difference among different age groups.

Prostate cancer is the second most common cancer among men worldwide. ${ }^{25}$ Studies have shown that the incidence of this disease is directly associated with age; with increases in age, mortality from this disease increases remarkably. ${ }^{26}$ According to the results of the current study, however, the difference between the levels of prostate cancer in different age groups seems to be decreasing. Because of the undesirable effects of this cancer on the quality and quantity of the patient's life, more efforts are needed to identify and prevent the risk factors of prostate cancer, such as smoking and a high-fat $\operatorname{diet}^{27}$ and to encourage the reasonable use of general screening methods. 
Similar to other studies, the current research found a statistically significant difference in the incidence of stomach cancer between males and females. ${ }^{28}$ The incidence and mortality rates of stomach cancer are higher in East Asia, Latin America, and some European countries ${ }^{29,30}$ than in others. Men may be more likely than women to have an inherent susceptibility, hormonal differences, or other risk factors for stomach cancer, such as unhealthy diet and Helicobacter pylori infection..$^{31,32}$ Further studies are needed to investigate the reasons for the difference between genders in the incidence of stomach cancer in different ethnicities.

\section{Conclusion}

The incidence of cancer has increased over 10 years in both genders and various ages, with increases in female and older age groups. It is suggested that future studies address the causes and factors of the increasing incidence of common cancers.

\section{Authors' Contributions}

All authors contributed equally to this study.

\section{Conflict of Interest Disclosures}

The authors declare that they have no conflicts of interest.

\section{Ethical Approval}

This study was approved by BMSU's Ethics Committee (No: IR.BMSU.REC.1395.297).

\section{Acknowledgments}

The authors extend their sincere appreciation for the guidance and advice of the Vice Chancellor of Research and Technology (Clinical Research Development Unit of Baqiyatallah Hospital), and special thanks to Dr. Hasan Saadat and Dr. Mohsen Saberi for their cooperation with the research team.

\section{References}

1. Torre LA, Bray F, Siegel RL, Ferlay J, Lortet-Tieulent J, Jemal A. Global cancer statistics, 2012. CA Cancer J Clin. 2015;65(2):87108. doi:10.3322/caac.21262.

2. Torre LA, Siegel RL, Ward EM, Jemal A. Global Cancer Incidence and Mortality Rates and Trends--An Update. Cancer Epidemiol Biomarkers Prev. 2016;25(1):16-27. doi:10.1158/1055-9965. epi-15-0578.

3. Ferlay J, Soerjomataram I, Dikshit R, et al. Cancer incidence and mortality worldwide: sources, methods and major patterns in GLOBOCAN 2012. Int J Cancer. 2015;136(5):E359-386. doi:10.1002/ijc.29210.

4. Jemal A, Bray F, Center MM, Ferlay J, Ward E, Forman D. Global cancer statistics. CA Cancer J Clin. 2011;61(2):69-90. doi:10.3322/caac.20107.

5. Popkin BM. Global changes in diet and activity patterns as drivers of the nutrition transition. Nestle Nutr Workshop Ser Pediatr Program. 2009;63:1-10; discussion 10-14, 259-268. doi:10.1159/000209967.

6. Shafey O, Dolwick S, Guindon GE. Tobacco control country profiles. Atlanta: American Cancer Society; 2003. p. 356.
7. Kanavos P. The rising burden of cancer in the developing world. Ann Oncol. 2006;17 Suppl 8:viii15-viii23. doi:10.1093/ annonc/mdl983.

8. Center MM, Jemal A, Smith RA, Ward E. Worldwide variations in colorectal cancer. CA Cancer J Clin. 2009;59(6):366-378. doi:10.3322/caac.20038.

9. Garcia M, Jemal A, Ward EM, et al. Global cancer facts \& figures 2007. Atlanta, GA:American Cancer Society; 2007;1(3):52.

10. Thun MJ, DeLancey JO, Center MM, Jemal A, Ward EM. The global burden of cancer: priorities for prevention. Carcinogenesis. 2010;31(1):100-110. doi:10.1093/carcin/ bgp263.

11. Pakzad R, Rafiemanesh H, Ghoncheh M, et al. Prostate Cancer in Iran: Trends in Incidence and Morphological and Epidemiological Characteristics. Asian Pac J Cancer Prev. 2016;17(2):839-843. doi:10.7314/apjcp.2016.17.2.839.

12. Enayatrad M, Amoori N, Salehiniya H. Epidemiology and trends in breast cancer mortality in iran. Iran J Public Health. 2015;44(3):430-431.

13. Rahimi F, Heidari M. Time trend analysis of stomach cancer incidence in the west of Iran. Health and Development Journal. 2012;1(2):100-111. [Persian].

14. Ferlay J, Wild CP, Bray F. The Burden of Cancer Worldwide: Current and Future Perspectives. Holland-Frei Cancer Medicine. 2016;17:1-5. doi:10.1002/9781119000822.hfcm034.

15. Boutayeb A, Boutayeb S. The burden of non communicable diseases in developing countries. Int J Equity Health. 2005;4(1):2. doi:10.1186/1475-9276-4-2.

16. Karim-Kos HE, de Vries E, Soerjomataram I, Lemmens V, Siesling S, Coebergh JW. Recent trends of cancer in Europe: a combined approach of incidence, survival and mortality for 17 cancer sites since the 1990s. Eur J Cancer. 2008;44(10):13451389. doi:10.1016/j.ejca.2007.12.015.

17. Jemal A, Vineis P, Bray F, Torre L, Forman D. The Cancer Atlas 2nd ed. Atlanta: American Cancer Society; 2014.

18. Mousavi SM, Montazeri A, Mohagheghi MA, et al. Breast cancer in Iran: an epidemiological review. Breast J. 2007;13(4):383391. doi:10.1111/j.1524-4741.2007.00446.x.

19. Smith RA. The value of modern mammography screening in the control of breast cancer: understanding the underpinnings of the current debates. Cancer Epidemiol Biomarkers Prev. 2014;23(7):1139-1146. doi:10.1158/1055-9965.epi-13-0946.

20. Moghimi-Dehkordi B, Safaee A, Zali MR. Prognostic factors in 1,138 Iranian colorectal cancer patients. Int J Colorectal Dis. 2008;23(7):683-688. doi:10.1007/s00384-008-0463-7.

21. Lieberman DA, Weiss DG, Bond JH, Ahnen DJ, Garewal H, Chejfec G. Use of colonoscopy to screen asymptomatic adults for colorectal cancer. Veterans Affairs Cooperative Study Group 380. N Engl J Med. 2000;343(3):162-168. doi:10.1056/ nejm200007203430301.

22. Thun M, Peto R, Boreham J, Lopez AD. Stages of the cigarette epidemic on entering its second century. Tob Control. 2012;21(2):96-101. doi:10.1136/tobaccocontrol-2011-050294.

23. Gu D, Wu X, Reynolds K, et al. Cigarette smoking and exposure to environmental tobacco smoke in China: the international collaborative study of cardiovascular disease in Asia. Am J Public Health. 2004;94(11):1972-1976. doi:10.2105/ ajph.94.11.1972.

24. World Health Organization (WHO). WHO report on the global tobacco epidemic. Geneva, Switzerland: WHO; 2008.

25. Center MM, Jemal A, Lortet-Tieulent J, et al. International variation in prostate cancer incidence and mortality rates. Eur Urol. 2012;61(6):1079-1092. doi:10.1016/j. eururo.2012.02.054 
26. Baade PD, Youlden DR, Krnjacki LJ. International epidemiology of prostate cancer: geographical distribution and secular trends. Mol Nutr Food Res. 2009;53(2):171-184. doi:10.1002/ mnfr.200700511.

27. Greenwald P. Clinical trials in cancer prevention: current results and perspectives for the future. J Nutr. 2004;134(12 Suppl):3507S-3512S. doi:10.1093/jn/134.12.3507S

28. Chen W, Zheng R, Baade PD, et al. Cancer statistics in China, 2015. CA Cancer J Clin. 2016;66(2):115-132. doi:10.3322/ caac. 21338.

29. Plummer M, Franceschi S, Vignat J, Forman D, de Martel C. Global burden of gastric cancer attributable to Helicobacter pylori. Int J Cancer. 2015;136(2):487-490. doi:10.1002/ ijc. 28999 .

30. Mohebbi M, Mahmoodi M, Wolfe R, et al. Geographical spread of gastrointestinal tract cancer incidence in the Caspian Sea region of Iran: spatial analysis of cancer registry data. BMC Cancer. 2008;8:137. doi:10.1186/1471-2407-8-137.

31. Uemura N, Okamoto $S$, Yamamoto $S$, et al. Helicobacter pylori infection and the development of gastric cancer. N Engl J Med. 2001;345(11):784-789. doi:10.1056/NEJMoa001999.

32. Jukic Z, Radulovic P, Stojkovic R, et al. Gender Difference in Distribution of Estrogen and Androgen Receptors in Intestinaltype Gastric Cancer. Anticancer Res. 2017;37(1):197-202. doi:10.21873/anticanres.11306. 